\title{
BMJ Open Evaluation of use and cost of medical care of common lumbar disorders in Korea: cross-sectional study of Korean Health Insurance Review and Assessment Service National Patient Sample data
}

\author{
Yong-Jun Ahn, ${ }^{1}$ Joon-Shik Shin, ${ }^{1}$ Jinho Lee, ${ }^{1}$ Yoon Jae Lee, ${ }^{1}$ Me-Riong Kim, ${ }^{1}$ \\ Ki Byung Park, ${ }^{1}$ Jun-Hwan Lee, ${ }^{2,3}$ Kyung-Min Shin, ${ }^{2}$ In-Hyuk $\mathrm{Ha}^{1}$
}

To cite: Ahn Y-J, Shin J-S, Lee $\mathrm{J}$, et al. Evaluation of use and cost of medical care of common lumbar disorders in Korea: cross-sectional study of Korean Health Insurance Review and Assessment Service National Patient Sample data. BMJ Open 2016;6:e012432.

doi:10.1136/bmjopen-2016012432

- Prepublication history for this paper is available online. To view these files please visit the journal online (http://dx.doi.org/10.1136/ bmjopen-2016-012432).

Received 26 April 2016 Revised 8 July 2016 Accepted 19 August 2016

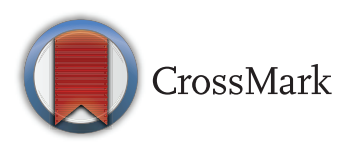

For numbered affiliations see end of article.

Correspondence to Dr In-Hyuk Ha; hanihata@gmail.com

\section{ABSTRACT}

Objectives: To assess medical care and costs of the 3 highest prevalence lumbar disorders-non-specific low back pain (nLBP), intervertebral disc disorder (IDD) and spinal stenosis (SS) - from national billing data to provide basic information for standards of appropriate management.

Design: Retrospective analysis of National Health Insurance National Patient Sample data provided by the Korean Health Insurance Review and Assessment Service (HIRA).

Setting: 2011 claims data from all medical institutions which filed billing statements to HIRA.

Participants: A total of 135561 patients with lumbar disorder who received medical services during 2011.

Outcome measures: Patient characteristics, medical procedures, medication, cost, injection and surgery.

Results: In the nLBP and IDD groups, the 50-59 age range had the highest prevalence, whereas prevalence increased with age in SS. All 3 groups showed a higher percentage in women. The average treatment cost was $196552 \mathrm{KRW}$ in the nLBP and $362050 \mathrm{KRW}$ in the IDD group, and highest in the SS group at $439025 \mathrm{KRW}$. While in the nLBP group women spent more on medical expenses, in the other 2 groups men showed higher expenditure. Expenditure grew with age in the nLBP and SS groups, whereas that of the IDD group peaked in their 40s. Analgesics were used in $73.43 \%$ of patients with nLBP, $82.64 \%$ of patients with IDD and $86.46 \%$ of patients with SS, and opioids in $4.12 \%$ of patients with IDD and $5.36 \%$ of patients with SS. Surgery rates were highest in the SS group at $4.85 \%$, with $0.9 \%$ for nLBP and $4.59 \%$ for IDD. The most frequent injection code was lumbar/caudal epidural nerve block. Expenditure and surgery rates were higher in the injection than in the non-injection subgroup in all 3 groups.

Conclusions: Patterns of medical care of most frequent lumbar disorders from HIRA data showed significant difference between groups and provide a basic standard for future usual care guidelines linked with health policy and budget appropriation.

\section{Strengths and limitations of this study}

- This study is the first to use age-stratified and gender-stratified random samples of the Korean National Health Insurance claims database, which represents $98 \%$ of the South Korean population, to examine and compare medical use and costs associated with most frequent lumbar disorders.

- National usage data on general management of most frequent lumbar disorders capture current clinical practice patterns, and surgery rates and diagnosis-related costs provide basic information for economic evaluation and health policy and budget appropriation.

- Definition of lumbar disorders reliant on the disease classification system of the Korean National Health Insurance claims database may have limited accuracy despite being used as the grounds for reimbursements, and the authors therefore attempted to address potential selection bias by including lumbar radiographs as a selection criterion.

- Although data were extracted from National Health Insurance claims statements that cover extensive information on healthcare interventions in a nationally representative sample, socioeconomic and clinical factors potentially influencing patterns of practice and non-reimbursable items and medicines could not be analysed.

\section{BACKGROUND}

Low back pain (LBP) is a common condition which $>90 \%$ of American adults experience at least once in their lifetime, ${ }^{1}$ and its treatment takes on significance as the most frequent cause of hospital visits, sick leave and absence from work. ${ }^{2}$ Moreover, studies report increasing prevalence over the past several decades, ${ }^{3}$ together with rise in costs. ${ }^{4}$ 
LBP is defined as localised pain between the 12th rib and gluteal folds with or without leg pain. Non-specific LBP (nLBP) is defined as back pain of unknown pathology. The greater majority of LBP cases are non-specific, with a specific cause identified in $\sim 5-10 \%$ of cases, which include intervertebral disc disorder (IDD) and spinal stenosis (SS) ${ }^{5}$

IDD is frequently associated with intervertebral disc degeneration and intervertebral disc herniation, affecting $10 \%$ of the population with low back and radiating pain over their lifetime. ${ }^{6}$ A 2008 study using data from the Medical Expenditure Panel Survey reported that IDD was the largest specific diagnosis among patients with spinal disorder, accounting for almost $16 \%$ of the total patients. ${ }^{7}$ Incidence of intervertebral disc herniation is highest in the 30-40 age range, and has been linked with dehydration and consequent degenerative disc change in this age group. ${ }^{8} 9$

While it has been stated that there is no accurate diagnostic and/or classification criteria for $\mathrm{SS},{ }^{10}$ it is still widely considered to refer to narrowing of the spinal canal and consequent nerve compression and ischaemia. ${ }^{11}$ This mainly degenerative disorder is characterised by neurogenic claudication and is caused by various primary or secondary structural pathologies of the spine, intervertebral disc, facet joint and surrounding ligaments. ${ }^{12}$ Prevalence of SS is increasing with marked growth of the ageing population over the past 20 years, and is especially prevalent in the $65+$ age group. ${ }^{13}$ Yearly SS incidence is estimated at 5 per 100000 population, ${ }^{14}$ and SS is the most common reason for spinal surgery in the elderly population aged 65 or older. ${ }^{15}$

These reports are in line with benefits by frequency of disease data from the 2013 Korean National Health Insurance Statistical Yearbook, in which spine-related Korean Standard Classification of Diseases (KCD) diagnoses with highest medical expense and number of patients were nLBP, IDD and SS. The number of patients with nLBP (KCD classification: dorsalgia, KCD code: M54) was 4568435 , with $~ 579.1$ billion KRW spent in annual medical expenses (seventh in overall disease diagnoses), number of patients with IDD (KCD classification: other IDDs, KCD code: M51) was 1847 234, with 587 billion KRW spent in medical expenses (sixth), and that of SS (KCD classification: other spondylopathies, KCD code: M48) was 1314 954, with a yearly medical expense of 468 billion KRW (ninth), showing that these three disorders incur considerable socioeconomic expense. ${ }^{16}$

Although medical expenditure and burden of disease of nLBP, IDD and SS are steadily increasing, reports on medical use and cost of each disease are scarce. Therefore, the objective of this study was to analyse billing data submitted to the Korean National Health Insurance and assessed by the Health Insurance Review and Assessment Service (HIRA) to compare medical care use and costs of most frequent lumbar disorders and thus provide basic information for future standards of the appropriate level of lumber disorder management in Korea.

\section{METHODS}

\section{Study population and sampling}

National Health Insurance billing data provided by HIRA include raw data of treatment prescriptions of all patients who received medical services over the course of 1 year after removal of identifying personal or corporate information. ${ }^{17}$ This study used the 2011 HIRA National Patient Sample (NPS) data set, which includes 3\% sample data of 2011 national insurance billing data ( 1.4 million patients) stratified by gender and 5-year age intervals.

National insurance billing statements contain charges to National Health Insurance and Medical Aid, and classify medical institutions into seven categories: upper level general hospitals, general hospitals, hospitals, clinics, Korean medicine hospitals, Korean medicine clinics and long-term care hospitals. Patients with lumbar disorder included for analysis were recategorised into three most frequent lumbar disorder groups, nLBP, IDD and SS, predefined as prefix codes M54, M51 and M48 through a literature review. Diagnoses were coded by the KCD, 6th revision (KCD-6) adapted from the International Classification of Diseases, 10th revision, and billing statements of patients aged $>120$, those with missing cost data, those with 0 total cost, those with no record of lumbar X-ray, those with lumbar/spinal diagnoses unrelated to IDD or SS within the predefined prefix codes or those with lumbar/spinal diagnoses pertaining to non-lumbar regions were excluded. Claims information of 135561 patients with lumbar disorder with the following prefix codes in primary or four secondary diagnoses were included for analysis through a panel discussion of four clinicians (one rehabilitation specialist and three Korean medicine rehabilitation specialists), and the flow chart of participant inclusion and exclusion is detailed in figure 1: M43, other deforming dorsopathies; M47, spondylosis; M48, other spondylopathies; M51, other IDDs; M54, dorsalgia; M99, biomechanical lesions, not elsewhere classified; and S33, dislocation, sprain and strain of joints and ligaments of lumbar spine and pelvis.

Of specific disease diagnoses, M541 (lumbar neuritis or radiculitis, not otherwise specified), initially classified as nLBP, was recategorised to the IDD group in accordance with a panel opinion with reference to clinical practice. Group classification of specific disease diagnoses is given in table 1. LBP-related diagnoses, injections, physiotherapy, surgical interventions and analgesics (opioid and non-opioid) were classified according to National Evidence-based healthcare Collaborating Agency reports. ${ }^{18}$

National Health Insurance-related terms are defined as follows. ${ }^{16}$

\section{Medical care institutions}

Medical care institutions that treat and medicate patients include tertiary and general hospitals, hospitals, clinics, dental hospitals and clinics, midwifery clinics, admission 


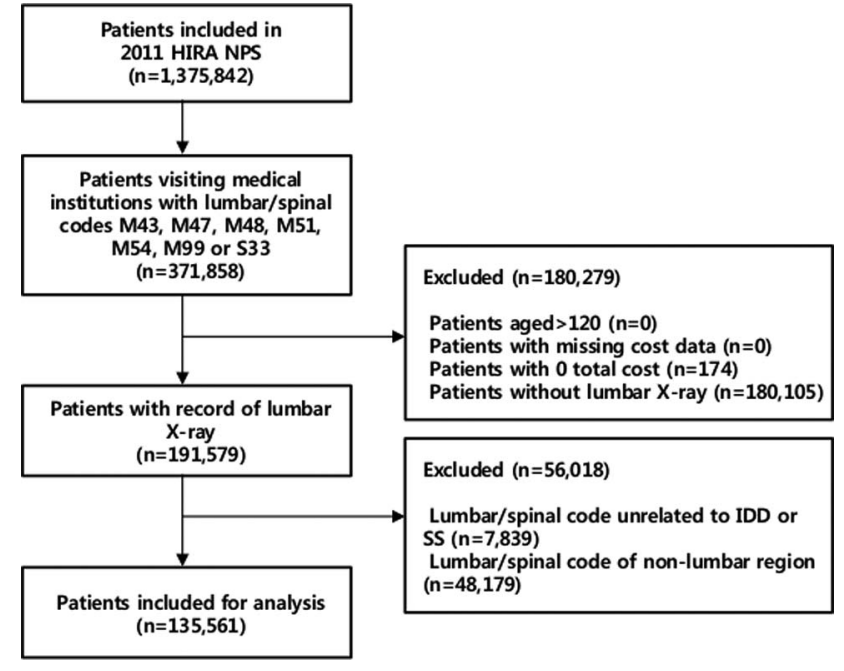

Figure 1 Flow chart of inclusion and exclusion process of most frequent lumbar disorders. HIRA, Health Insurance Review and Assessment Service; IDD, intervertebral disc disorder; M43, other deforming dorsopathies; M47, spondylosis; M48, other spondylopathies; M51, other IDDs; M54, dorsalgia; M99, biomechanical lesions, not elsewhere classified; NPS, National Patient Sample; S33, dislocation, sprain and strain of joints and ligaments of the lumbar spine and pelvis; SS, spinal stenosis.

facility-equipped health centres, health centres, health subcentres, primary healthcare centres, Korean medicine hospitals and clinics, and pharmacies. The term 'medical institution' is used to indicate medical care institutions with the exception of pharmacies.

\section{Treatment amount}

Treatment amount refers to the total medical care institution expenditure for patients who are covered by medical insurance, and comprises two kinds of costs: the amount paid by the insurer and that by the beneficiary. Generally speaking, it is the finalised total medical care cost adjusted and determined to be eligible for reimbursement through review by the HIRA from the initial non-adjusted estimate submitted by the medical care institution.

\section{Benefit amount}

The benefit amount is the reimbursement sum paid by the insurer (Korean National Health Insurance Service) to the medical care institution, and is determined by excluding the beneficiary-paid sum as decreed by law from the adjusted total treatment amount (or medication cost) determined to be valid through HIRA review.

\section{Visit (admission) days}

The number of visits (in the outpatient department) or the length of hospital stay (in the inpatient department) of patient indicated in the submitted insurance claim statement is tallied.
Table 1 Group classification of specific disease diagnoses of $n L B P$, IDD and SS groups

\begin{tabular}{|c|c|}
\hline $\begin{array}{l}\text { KCD-6 } \\
\text { code* }^{\star}\end{array}$ & Disease diagnosis \\
\hline \multicolumn{2}{|c|}{ nLBP group } \\
\hline S33 & $\begin{array}{l}\text { Dislocation, sprain and strain of joints and } \\
\text { ligaments of the lumbar spine and pelvis }\end{array}$ \\
\hline S335 & Sprain and strain of the lumbar spine \\
\hline S336 & Sprain and strain of the sacroiliac joint \\
\hline S337 & $\begin{array}{l}\text { Sprain and strain of other and unspecified } \\
\text { parts of the lumbar spine and pelvis }\end{array}$ \\
\hline M544 & Lumbago with sciatica \\
\hline M545 & LBP \\
\hline \multicolumn{2}{|c|}{ IDD group } \\
\hline M541 & $\begin{array}{l}\text { Lumbar neuritis or radiculitis, not otherwise } \\
\text { specified }\end{array}$ \\
\hline M51 & Other IDDs \\
\hline M510 & $\begin{array}{l}\text { Lumbar disorders and other IDDs with } \\
\text { myelopathy }\end{array}$ \\
\hline M511 & $\begin{array}{l}\text { Lumbar disorders and other IDDs with } \\
\text { radiculopathy }\end{array}$ \\
\hline M512 & $\begin{array}{l}\text { Other specified intervertebral disc } \\
\text { displacement }\end{array}$ \\
\hline M513 & $\begin{array}{l}\text { Other specified intervertebral disc } \\
\text { degeneration, multiple sites in the spine }\end{array}$ \\
\hline M514 & Schmorl's nodes \\
\hline M518 & Other specified IDDs \\
\hline M519 & IDD, unspecified \\
\hline \multicolumn{2}{|c|}{ SS group } \\
\hline M480 & SS \\
\hline M993 & Osseous stenosis of the neural canal \\
\hline M994 & Connective tissue stenosis of the neural canal \\
\hline M995 & Intervertebral disc stenosis of the neural canal \\
\hline M996 & $\begin{array}{l}\text { Osseous and subluxation stenosis of the } \\
\text { intervertebral foramina }\end{array}$ \\
\hline M997 & $\begin{array}{l}\text { Connective tissue and disc stenosis of the } \\
\text { intervertebral foramina }\end{array}$ \\
\hline \multicolumn{2}{|c|}{$\begin{array}{l}{ }^{*} \text { Diagnoses were coded by the KCD- } 6 \text { which is the Korean version } \\
\text { adapted from the International Classification of Diseases, 10th } \\
\text { revision (ICD-10). } \\
\text { IDD, intervertebral disc disorder; KCD-6, Korean Standard } \\
\text { Classification of Diseases, 6th revision; LBP, low back pain; nLBP, } \\
\text { non-specific low back pain; SS, spinal stenosis. }\end{array}$} \\
\hline
\end{tabular}

\section{Days of medication}

Days of medication represent the total sum of visit days and in-care drug prescription days. Outpatient visits with drug prescription coinciding with hospitalisation and drug prescription on the same day were tallied as 1 day. Days of medication at the pharmacy indicate the number of days of receiving medication.

\section{Statistical analysis}

Patient sociodemographic characteristics and frequency of prescriptions (surgical or medical interventions, including prescription medicine (analgesics)) are presented for each operational definition. The average treatment amount and benefit by group, and proportion of recipients of injection and non-injection treatment 
were also calculated, and descriptive statistics are presented by age and gender. All statistical analyses were performed using SAS 9.3 (SAS Institute., Cary, North Carolina, USA).

\section{RESULTS}

While the 50-59 age range was most prevalent for the nLBP and IDD groups, prevalence increased with age in the SS group. All three groups showed a higher percentage of women than men. In use of medical institutions, clinics were most frequently visited in all three groups, followed by hospitals and general hospitals in the IDD and SS groups, and Korean medicine clinics in the nLBP group. In visits by medical specialty, visits to orthopaedics were most frequent in all three groups, followed by neurosurgery, and anaesthesiology and pain medicine specialists in the IDD and SS groups, and internal Korean medicine, and acupuncture and moxibustion specialists in the nLBP group. Visits to medical institutions located in Seoul were most common, followed by Gyeonggi-do, Busan and Gyeongsangnam-do (table 2).

The average treatment amount and the benefit per patient were 196552 and $147040 \mathrm{KRW}$ in the nLBP group, 362050 and $237321 \mathrm{KRW}$ in the IDD group, and highest in the SS group at 439025 and 275224 KRW, respectively. Women in the nLBP group spent more on medical expenses, but in the other two groups, men showed higher expenditure. While expenditure increased with age in the nLBP and SS groups, that of the IDD group peaked in patients in their 40s at 368073 KRW. In expense by medical institution, long-term care hospitals had the highest expense in all three groups, followed by Korean medicine hospitals and upper level general hospitals. Analysis by medical specialty revealed that expense was highest in the anaesthesiology and pain medicine specialty in the nLBP group, and highest in the neurosurgery specialty in the IDD and SS groups. The average treatment amounts per patient in inpatient and outpatient care were highest in the SS group at 198448 and 2248111 KRW, respectively. The average surgical treatment amount per patient was also highest in the SS group at 3413085 KRW (table 3).

Surgery rates were highest in the SS group at $0.9 \%$ for nLBP, $4.59 \%$ for IDD and $4.85 \%$ for SS. The most frequently used surgery code was open lumbar discectomy in the nLBP and IDD groups, and lumbar laminectomy closely followed by open lumbar discectomy in the SS group. The most frequent injection code for all three groups was epidural nerve block (lumbar and/or caudal), and in the IDD and SS groups, selective spinal nerve plexus, root or ganglion block and spinal nerve plexus, root or ganglion block (posterior division) followed.

Analgesics were used in $73.43 \%$ of the nLBP, $82.64 \%$ of the IDD and $86.46 \%$ of the SS group, and opioid analgesics were used in $4.12 \%$ of the IDD and $5.36 \%$ of the SS group. Of non-opioid analgesics, aceclofenac $100 \mathrm{mg}$ was used most commonly in all three groups, followed by tramadol $\mathrm{HCl} 50 \mathrm{mg}$ and talniflumate $370 \mathrm{mg}$. Of opioid analgesics, the nLBP and SS groups showed highest use in codeine phosphate $10 \mathrm{mg}$, while in the IDD group, pethidine $\mathrm{HCl} 50 \mathrm{mg}$ was most commonly used, followed by codeine phosphate $10 \mathrm{mg}$. Deep heat therapy was most frequently prescribed as physiotherapy in all three groups, followed by superficial heat therapy and transcutaneous electrical nerve stimulation (table 4).

A total $6876(6.16 \%)$ of 111544 patients with nLBP, $9546(19.72 \%)$ of 48413 patients with IDD and 7138 $(24.75 \%)$ of 28842 patients with SS received injection treatment. More women received injections compared to men in all three groups. In injections by age group, the proportion of recipients aged 60-69 was largest in the nLBP group, 50-59 in the IDD group and increased with age in the SS group. Surgery rates were higher in injection recipients than non-recipients in all groups with $1.0 \%$ in the nLBP, $7 \%$ in the IDD and $5.7 \%$ in the SS group, as was the average expenditure per patient in the injection compared to the non-injection subgroup in all three groups, at 407083 in the nLBP, 615312 in the IDD and $648545 \mathrm{KRW}$ in the SS group. While patients aged $70+$ had highest medical expense by age in the injection and non-injection subgroups in the nLBP and SS groups, patients aged 30-39 showed highest average spending in the IDD group.

The average number of reimbursed days per injection patient was also higher than that for non-injection patients in all three groups at 15.4 days in the nLBP, 15.6 days in the IDD and highest at 16.5 days in the SS group. Similar to medical expense, patients aged $70+$ spent most number of reimbursed days in medical care when categorised by age in the injection and noninjection subgroups in the nLBP and SS groups, and in patients aged 30-39 in the IDD group (table 5).

\section{DISCUSSION}

This study used 2011 HIRA NPS data, which consist of $3 \%$ age-stratified and gender-stratified random samples that appropriately reflect the South Korean population of 2011 to capture real-world medical use and cost in most frequent lumbar disorders. This study is descriptive in nature, and reports sociodemographic characteristics, procedures, medication, average cost and benefits in most frequent lumbar disorders without addressing a specific hypothesis. Difference in current usage patterns were especially marked in the injection subgroup and the SS group.

The National Health Insurance claims database is representative of the population as it is a National Health Insurance scheme that covers $\sim 98 \%$ of the overall South Korean population. National Health Insurance was established in 1989 in South Korea and Employees' Health Insurance was merged into the National Health Insurance service in $2000{ }^{19}$ About $54 \%$ of medical 
Table 2 Sociodemographic characteristics and medical care use by group*

\begin{tabular}{|c|c|c|c|c|c|c|}
\hline & \multicolumn{2}{|l|}{ nLBP } & \multicolumn{2}{|l|}{ IDD } & \multicolumn{2}{|l|}{ SS } \\
\hline & $\bar{n}$ & Per cent & $\mathrm{n}$ & Per cent & $\mathrm{n}$ & Per cent \\
\hline \multicolumn{7}{|l|}{ Age (years) } \\
\hline$<20$ & 9069 & 8.0 & 884 & 1.8 & 53 & 0.2 \\
\hline $20-29$ & 11130 & 9.8 & 3406 & 6.9 & 270 & 0.9 \\
\hline $30-39$ & 16201 & 14.3 & 6513 & 13.2 & 771 & 2.6 \\
\hline $40-49$ & 19676 & 17.3 & 9207 & 18.7 & 2369 & 8.1 \\
\hline $50-59$ & 22984 & 20.2 & 11942 & 24.3 & 6299 & 21.5 \\
\hline $60-69$ & 17646 & 15.5 & 9353 & 19.0 & 9061 & 30.9 \\
\hline$\geq 70$ & 16927 & 14.9 & 7894 & 16.0 & 10472 & 35.7 \\
\hline \multicolumn{7}{|l|}{ Gender } \\
\hline Male & 45938 & 41.2 & 19067 & 39.4 & 9828 & 34.1 \\
\hline Female & 65606 & 58.8 & 29346 & 60.6 & 19014 & 65.9 \\
\hline \multicolumn{7}{|l|}{ Treatment type used } \\
\hline Inpatient & 6142 & 5.3 & 6782 & 12.7 & 3163 & 10.2 \\
\hline Outpatient & 109305 & 94.7 & 46669 & 87.3 & 27975 & 89.8 \\
\hline \multicolumn{7}{|l|}{ Public insurance scheme } \\
\hline Health insurance & 105613 & 94.4 & 45458 & 93.4 & 26262 & 90.1 \\
\hline Medical aid & 6224 & 5.6 & 3034 & 6.2 & 2665 & 9.1 \\
\hline Veteran healthcare & 98 & 0.1 & 165 & 0.3 & 230 & 0.8 \\
\hline \multicolumn{7}{|l|}{ Medical institution visited } \\
\hline Clinic & 74988 & 47.9 & 30399 & 53.3 & 16080 & 47.7 \\
\hline Hospital & 20605 & 13.2 & 15421 & 27.1 & 9179 & 27.2 \\
\hline Korean medicine clinic & 41295 & 26.4 & 2521 & 4.4 & 598 & 1.8 \\
\hline General hospital & 10345 & 6.6 & 5356 & 9.4 & 5377 & 16.0 \\
\hline Upper level general hospital & 2351 & 1.5 & 1689 & 3.0 & 1911 & 5.7 \\
\hline Korean medicine hospital & 3471 & 2.2 & 1135 & 2.0 & 188 & 0.6 \\
\hline Long-term care hospital & 1346 & 0.9 & 366 & 0.6 & 219 & 0.6 \\
\hline \multicolumn{7}{|l|}{ Visits by medical specialty } \\
\hline Orthopaedics & 72196 & 41.6 & 29682 & 49.0 & 20082 & 56.9 \\
\hline Neurosurgery & 13685 & 7.9 & 14375 & 23.7 & 7469 & 21.2 \\
\hline Acupuncture and moxibustion medicine & 23883 & 13.8 & 1851 & 3.1 & 359 & 1.0 \\
\hline Internal Korean medicine & 24361 & 14.0 & 892 & 1.5 & 344 & 1.0 \\
\hline Internal medicine & 9705 & 5.6 & 2112 & 3.5 & 1642 & 4.7 \\
\hline Anaesthesiology and pain medicine & 4795 & 2.8 & 3090 & 5.1 & 2356 & 6.7 \\
\hline Surgery & 6586 & 3.8 & 1574 & 2.6 & 704 & 2.0 \\
\hline Other & 18359 & 10.6 & 7028 & 11.6 & 2324 & 6.6 \\
\hline \multicolumn{7}{|l|}{ Location of medical institution visited } \\
\hline Seoul & 23836 & 19.8 & 11283 & 22.0 & 6662 & 21.7 \\
\hline Busan & 7544 & 6.3 & 3654 & 7.1 & 2610 & 8.5 \\
\hline Incheon & 6320 & 5.3 & 2595 & 5.1 & 1037 & 3.4 \\
\hline Daegu & 5886 & 4.9 & 2498 & 4.9 & 1648 & 5.4 \\
\hline Gwangju & 4204 & 3.5 & 1684 & 3.3 & 857 & 2.8 \\
\hline Daejeon & 3818 & 3.2 & 1440 & 2.8 & 1160 & 3.8 \\
\hline Ulsan & 2355 & 2.0 & 940 & 1.8 & 495 & 1.6 \\
\hline Gyeonggi-do & 25289 & 21.1 & 10967 & 21.4 & 4775 & 15.6 \\
\hline Gangwon-do & 4013 & 3.3 & 1702 & 3.3 & 1181 & 3.9 \\
\hline Chungcheongbuk-do & 4262 & 3.5 & 1773 & 3.5 & 1103 & 3.6 \\
\hline Chungcheongnam-do & 5516 & 4.6 & 2147 & 4.2 & 1420 & 4.6 \\
\hline Jeollabuk-do & 5567 & 4.6 & 2176 & 4.2 & 1807 & 5.9 \\
\hline Jeollanam-do & 5627 & 4.7 & 2276 & 4.4 & 1659 & 5.4 \\
\hline Gyeongsangbuk-do & 6693 & 5.6 & 2322 & 4.5 & 1882 & 6.1 \\
\hline Gyeongsangnam-do & 7826 & 6.5 & 3147 & 6.1 & 1993 & 6.5 \\
\hline Jeju-do & 1344 & 1.1 & 680 & 1.3 & 365 & 1.2 \\
\hline
\end{tabular}

*Patients with overlapping records tallied as separate patients.

IDD, intervertebral disc disorder; nLBP, non-specific low back pain; SS, spinal stenosis. 
Table 3 Average treatment amount and benefit per patient by group ${ }^{*}$

\begin{tabular}{|c|c|c|c|c|c|c|}
\hline & \multicolumn{2}{|l|}{ nLBP } & \multicolumn{2}{|l|}{ IDD } & \multicolumn{2}{|l|}{ SS } \\
\hline & $\begin{array}{l}\text { Treatment } \\
\text { amount } \\
(1000 \mathrm{KRW})\end{array}$ & $\begin{array}{l}\text { Benefit } \\
\text { amount } \\
(1000 \mathrm{KRW})\end{array}$ & $\begin{array}{l}\text { Treatment } \\
\text { amount } \\
(1000 \mathrm{KRW})\end{array}$ & $\begin{array}{l}\text { Benefit } \\
\text { amount } \\
(1000 \mathrm{KRW})\end{array}$ & $\begin{array}{l}\text { Treatment } \\
\text { amount } \\
(1000 \mathrm{KRW})\end{array}$ & $\begin{array}{l}\text { Benefit } \\
\text { amount } \\
(1000 \mathrm{KRW})\end{array}$ \\
\hline \multicolumn{7}{|l|}{ Gender } \\
\hline Male & 171474 & 125838 & 383252 & 279748 & 465278 & 348887 \\
\hline Female & 214112 & 161886 & 348273 & 258935 & 425456 & 323244 \\
\hline \multicolumn{7}{|l|}{ Age (years) } \\
\hline$<20$ & 92295 & 66007 & 260547 & 189332 & 191796 & 149186 \\
\hline 20-29 & 130363 & 91517 & 299123 & 211662 & 152432 & 104315 \\
\hline 30-39 & 145282 & 101858 & 355044 & 255253 & 245619 & 181799 \\
\hline $40-49$ & 173030 & 124379 & 368073 & 269164 & 346966 & 258196 \\
\hline $50-59$ & 198927 & 142743 & 360440 & 263106 & 354449 & 259792 \\
\hline $60-69$ & 229733 & 175831 & 354971 & 263339 & 462022 & 347040 \\
\hline$\geq 70$ & 310271 & 254221 & 374094 & 291192 & 494715 & 382559 \\
\hline \multicolumn{7}{|l|}{ Treatment } \\
\hline Inpatient & 937692 & 722549 & 1343232 & 1045275 & 2248111 & 1791462 \\
\hline Outpatient & 147888 & 109451 & 180379 & 125214 & 198448 & 139719 \\
\hline \multicolumn{7}{|l|}{ Treatment amount } \\
\hline Total medical cost & 196552 & & 362050 & & 439025 & \\
\hline Self-payment cost & 49122 & & 92824 & & 101551 & \\
\hline Insurer-payment cost & 147040 & & 267132 & & 331982 & \\
\hline \multicolumn{7}{|l|}{ Public insurance scheme } \\
\hline Health insurance & 190655 & 139208 & 351763 & 252748 & 415485 & 302262 \\
\hline Medical aid & 283488 & 271834 & 474312 & 458457 & 586665 & 570524 \\
\hline Veteran healthcare & 245792 & 74441 & 596402 & 316720 & 814934 & 506786 \\
\hline \multicolumn{7}{|l|}{ Medical institution } \\
\hline Clinic & 126671 & 96508 & 199340 & 150026 & 214131 & 167145 \\
\hline Hospital & 152812 & 109882 & 444272 & 327561 & 422746 & 315882 \\
\hline Korean medicine clinic & 136645 & 106555 & 128753 & 99095 & 168161 & 133518 \\
\hline General hospital & 178256 & 122719 & 486909 & 353055 & 564216 & 422531 \\
\hline Upper level general hospital & 185901 & 101046 & 515959 & 341424 & 963936 & 707015 \\
\hline Korean medicine hospital & 249263 & 178340 & 536411 & 386986 & 432867 & 314565 \\
\hline Long-term care hospital & 294487 & 223931 & 541724 & 435586 & 1232065 & 990993 \\
\hline \multicolumn{7}{|l|}{ Medical specialty } \\
\hline Orthopaedics & 131039 & 97302 & 252103 & 187903 & 339495 & 259354 \\
\hline Neurosurgery & 118663 & 82131 & 453336 & 333135 & 509032 & 379142 \\
\hline $\begin{array}{l}\text { Acupuncture and } \\
\text { moxibustion medicine }\end{array}$ & 135117 & 105014 & 186092 & 141673 & 205936 & 159482 \\
\hline Internal Korean medicine & 124159 & 96030 & 165971 & 127618 & 184338 & 148624 \\
\hline Internal medicine & 95444 & 74950 & 178691 & 139797 & 234269 & 187210 \\
\hline $\begin{array}{l}\text { Anaesthesiology and pain } \\
\text { medicine }\end{array}$ & 152421 & 109188 & 223162 & 155804 & 249957 & 171768 \\
\hline Surgery & 134784 & 103408 & 219405 & 170091 & 226691 & 177391 \\
\hline \multicolumn{7}{|l|}{ Surgery } \\
\hline No & 185196 & 138068 & 262652 & 189166 & 275390 & 201397 \\
\hline Yes & 1320929 & 1040705 & 2194448 & 1719504 & 3413085 & 2721099 \\
\hline
\end{tabular}

*Patients with overlapping records tallied as separate patients.

IDD, intervertebral disc disorder; nLBP, non-specific low back pain; SS, spinal stenosis.

expenditure is covered by the National Health Insurance service, and the remaining $46 \%$ is mostly paid through out-of-pocket expenses. ${ }^{20}$

Claims were filed to HIRA for 45.8 billion patients in 2011, which accounts for $90.3 \%$ of the total registered population of 50 billion. The total number of filed claims and total health expenditures have risen steadily, and as of 2011, the total number of filed claims reached 1.3 billion and with it, the total health expenditure $\sim 51.5$ trillion KRW. The number of registered medical care institutions has also increased from 7289 in the 1980s to 82948 in 2011 . $^{21}$

The National Health Insurance claims database covers all insurance billing codes submitted by registered medical care institutions to claim reimbursable medical costs from the National Health Insurance after HIRA review. Four different random sample data sets are available by year for 2009-2011: NPS, National Inpatient 
Table 4 Use of surgery and injection procedures, physiotherapy and analgesics by group*

\begin{tabular}{|c|c|c|c|c|c|c|c|}
\hline & \multirow[t]{2}{*}{ Code } & \multicolumn{2}{|l|}{ nLBP } & \multicolumn{2}{|l|}{ IDD } & \multicolumn{2}{|l|}{ ss } \\
\hline & & $\mathbf{n}$ & Per cent & $\bar{n}$ & Per cent & $\bar{n}$ & Per cent \\
\hline Total & & 111544 & 100.0 & 48413 & 100.0 & 28842 & 100.0 \\
\hline \multicolumn{8}{|l|}{ Surgical intervention } \\
\hline No & & 111194 & 99.69 & 48178 & 99.51 & 28641 & 99.30 \\
\hline Yes & & 1008 & 0.90 & 2221 & 4.59 & 1399 & 4.85 \\
\hline \multicolumn{8}{|l|}{ Surgery procedure code } \\
\hline Open lumbar discectomy & N1493 & 6 & 0.01 & 1667 & 3.44 & 436 & 1.51 \\
\hline Lumbar laminectomy & N1499 & 4 & 0.00 & 121 & 0.25 & 451 & 1.56 \\
\hline Lumbar arthrodesis (posterior technique) & N0469 & - & - & 25 & 0.05 & 103 & 0.36 \\
\hline Endoscopic discectomy & N1494 & - & - & 53 & 0.11 & - & - \\
\hline Lumbar arthrodesis (anterior technique) & N0466 & - & - & 6 & 0.01 & 19 & 0.07 \\
\hline Other & & 1 & 0.00 & 10 & 0.02 & 5 & 0.02 \\
\hline \multicolumn{8}{|l|}{ Non-surgical intervention } \\
\hline Epidural nerve block (lumbar and/or caudal) & LA322 & 4480 & 4.02 & 6830 & 14.11 & 5202 & 18.04 \\
\hline Spinal nerve plexus, root or ganglion block (posterior division) & LA357 & 1149 & 1.03 & 740 & 1.53 & 494 & 1.71 \\
\hline Selective spinal nerve plexus, root or ganglion block & LA354 & 395 & 0.35 & 968 & 2.00 & 807 & 2.80 \\
\hline Spinal nerve plexus, root or ganglion block (posterior medial branch) & LA358 & 588 & 0.53 & 862 & 1.78 & 629 & 2.18 \\
\hline Spinal nerve plexus, root or ganglion block (facet joint) & LA359 & 416 & 0.37 & 618 & 1.28 & 532 & 1.84 \\
\hline Spinal nerve plexus, root or ganglion block (lumbar or sacral plexus) & LA253 & 419 & 0.38 & 447 & 0.92 & 340 & 1.18 \\
\hline Spinal nerve plexus, root or ganglion block (dorsal root ganglion) & LA355 & 62 & 0.06 & 312 & 0.64 & 259 & 0.90 \\
\hline Spinal nerve plexus, root or ganglion block (gray rami communicans) & LA356 & 1 & 0.00 & 3 & 0.01 & 2 & 0.01 \\
\hline \multicolumn{8}{|l|}{ Physiotherapy } \\
\hline Deep heat therapy & MM020 & 56380 & 50.55 & 25663 & 53.01 & 12757 & 44.23 \\
\hline Superficial heat therapy with deep heat therapy & MM015 & 56078 & 50.27 & 25512 & 52.70 & 12651 & 43.86 \\
\hline Transcutaneous electrical nerve stimulation with interferential current therapy & MM080 & 34326 & 30.77 & 16913 & 34.93 & 8228 & 28.53 \\
\hline Transcutaneous electrical nerve stimulation & MM070 & 31940 & 28.63 & 14121 & 29.17 & 7141 & 24.76 \\
\hline Superficial heat therapy & MM010 & 13001 & 11.66 & 7751 & 16.01 & 3730 & 12.93 \\
\hline Intermittent pelvic traction therapy & MM052 & 4510 & 4.04 & 13929 & 28.77 & 3095 & 10.73 \\
\hline Rehabilitation low output laser therapy & MM085 & 5281 & 4.73 & 2885 & 5.96 & 1348 & 4.67 \\
\hline Simple therapeutic exercise & MM101 & 3673 & 3.29 & 2401 & 4.96 & 851 & 2.95 \\
\hline Other & & 1000 & 0.90 & 701 & 1.45 & 500 & 1.73 \\
\hline \multicolumn{8}{|l|}{ Analgesics } \\
\hline Non-opioid analgesics & & 81150 & 72.75 & 38014 & 78.52 & 23391 & 81.10 \\
\hline Opioid analgesics & & 761 & 0.68 & 1994 & 4.12 & 1545 & 5.36 \\
\hline \multicolumn{8}{|l|}{ Non-opioid analgesics } \\
\hline Aceclofenac $100 \mathrm{mg}$ & 100901AT & 25102 & 22.50 & 14044 & 29.01 & 8036 & 27.86 \\
\hline Tramadol $\mathrm{HCl} 50 \mathrm{mg}$ & 242303BI & 24344 & 21.82 & 9489 & 19.60 & 5919 & 20.52 \\
\hline Talniflumate 370 mg & 234401AT & 20245 & 18.15 & 8378 & 17.31 & 3978 & 13.79 \\
\hline Diclofenac sodium $75 \mathrm{mg}$ & $143502 B \mathrm{I}$ & 18249 & 16.36 & 7065 & 14.59 & 3806 & 13.20 \\
\hline Loxoprofen sodium $60 \mathrm{mg}$ & 186101AT & 18589 & 16.67 & 6831 & 14.11 & 3288 & 11.40 \\
\hline Acetaminophen $162.5 \mathrm{mg}$ & 480600AT & 9889 & 8.87 & 5609 & 11.59 & 4024 & 13.95 \\
\hline
\end{tabular}




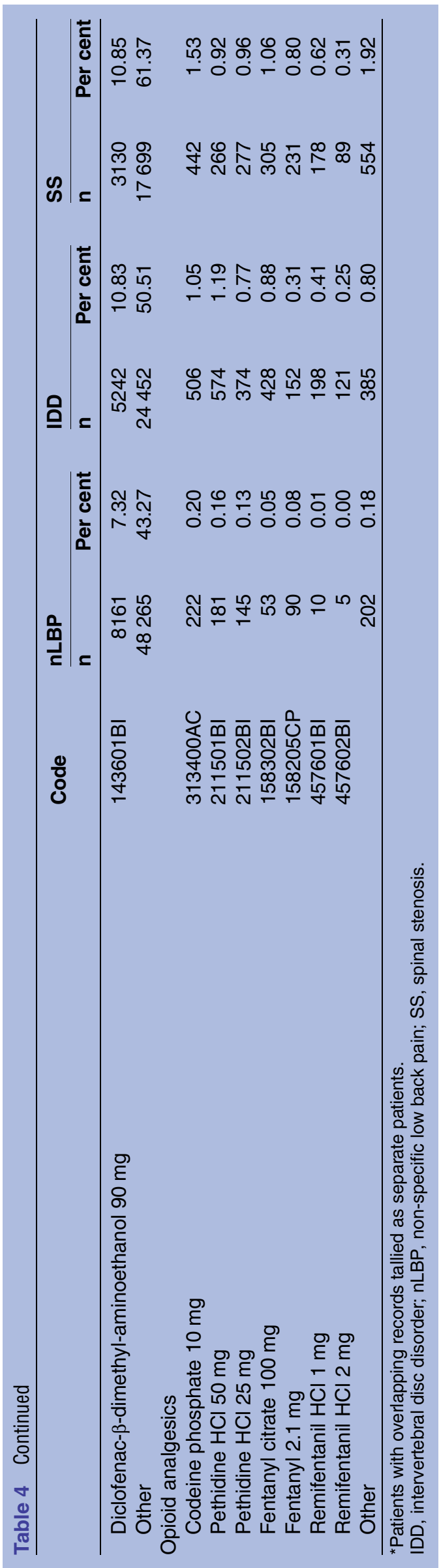

Sample, Aged Patient Sample and Paediatric Patient Sample. Claims statements cover extensive information on healthcare interventions (eg, treatment, procedures, diagnostic tests and prescription drugs), diagnosis, National Health Insurance-payment cost, beneficiaries' self-payment cost, sociodemographic characteristics and medical institutions, and thus provide a useful source of nationwide epidemiological data of which the representativeness, reliability and validity have been confirmed. ${ }^{19}$

The large variations in diagnostic and therapeutic management of LBP and lumbar disorders among clinicians within and between countries, ${ }^{22-26}$ coupled with the significant costs of these conditions, indicate that more systematic and scientifically based approaches are needed. ${ }^{27}$ This study assesses medical care and costs of most frequently used treatments in high prevalence lumbar disorders in Korea to provide a basic standard for future usual care guidelines that may reduce health expenditures and help solve National Health Insurance deficits. This study is the first to use HIRA NPS 2011 billing data to examine and compare medical use and costs associated with most frequent lumbar disorders. To date, no studies have reported national usage data on management of most frequent lumbar disorders, and this study holds significance in that it is the first report on prevalence and treatment patterns of most frequent lumbar disorders in Korea on a national level. Such national usage data on general management of most frequent lumbar disorders captures current clinical practice patterns, and surgery rates and diagnosis-related costs provide basic information for economic evaluation and health policy and budget appropriation.

An added strength of this study is that it acts as a window onto patterns of complementary and alternative medicine (CAM) treatment for LBP in Korea, which covers such CAM treatments as acupuncture and moxibustion in National Health Insurance. Of the nLBP group, $26.4 \%$ visited Korean medicine clinics for treatment and 2.2\% visited Korean medicine hospitals, resulting in an approximate rate of Korean medicine use, including acupuncture, of about $30 \%$. Korean medicine holds various medical specialties (4 years of specialist training following 6 years of undergraduate education), of which acupuncture specialists, who specialise in acupuncture and moxibustion (13.8\% of nLBP), and internal Korean Medicine specialists $(14.0 \%$ of nLBP) were shown to treat LBP most frequently following conventional medicine orthopaedics $(41.6 \%$ of nLBP). It is also worthy of note that Korean medicine doctors are precluded from diagnosing IDD or SS independently due to regulation restrictions in imaging device use, which may be associated with the fact that Korean medicine use for IDD and SS is much lower compared to that of nLBP.

The results show that the proportion of patients in the 50-59 age range was highest in the nLBP and IDD groups, and prevalence increased with age in the SS group. Prevalence of lumbar disc degeneration has been 
Table 5 Comparison of patient characteristics in the injection and non-injection subgroups*

\begin{tabular}{|c|c|c|c|c|c|c|c|c|c|c|c|c|c|c|c|c|c|c|}
\hline & \multicolumn{3}{|l|}{$\mathbf{N}$} & \multicolumn{3}{|c|}{$\begin{array}{l}\text { Visit days per } \\
\text { patient† (days) }\end{array}$} & \multicolumn{3}{|c|}{$\begin{array}{l}\text { Reimbursed } \\
\text { visit days per } \\
\text { patient‡ (days) }\end{array}$} & \multicolumn{3}{|c|}{$\begin{array}{l}\text { Benefit amount per patient§ } \\
\text { (1000 KRW) }\end{array}$} & \multicolumn{3}{|c|}{$\begin{array}{l}\text { Treatment amount per } \\
\text { patientๆ (1000 KRW) }\end{array}$} & \multicolumn{3}{|c|}{ Surgery rate (\%) } \\
\hline & nLBP & IDD & SS & nLBP & IDD & SS & nLBP & IDD & SS & nLBP & IDD & SS & nLBP & IDD & SS & nLBP & IDD & SS \\
\hline $\begin{array}{l}\text { Non-injection } \\
\text { group }\end{array}$ & 95199 & 35152 & 18769 & 7.2 & 7.5 & 7.8 & 7.9 & 9.4 & 12.0 & 131670.4 & 216818.0 & 278164.9 & 177044 & 294237 & 366803 & $888(0.9 \%)$ & 1354 (3.9\%) & $841(4.5 \%)$ \\
\hline $\begin{array}{l}\text { Injection } \\
\text { group }\end{array}$ & 6876 & 9546 & 7138 & 14.1 & 12.5 & 12.4 & 15.4 & 15.6 & 16.5 & 303823.8 & 452656.1 & 486879.6 & 407083 & 615312 & 648545 & $69(1.0 \%)$ & $665(7.0 \%)$ & 409 (5.7\%) \\
\hline \multicolumn{19}{|c|}{ Non-injection group } \\
\hline \multicolumn{19}{|l|}{ Gender } \\
\hline Male & 40083 & 14020 & 6527 & 6.0 & 7.3 & 7.5 & 6.7 & 10.1 & 15.5 & 114337.4 & 230789.5 & 301476.3 & 156465 & 316138 & 400303 & $448(1.1)$ & $727(5.2)$ & $340(5.2)$ \\
\hline Female & 55116 & 21132 & 12242 & 8.0 & 7.6 & 7.9 & 8.7 & 8.9 & 10.1 & 144275.8 & 207548.6 & 265736.1 & 192010 & 279706 & 348943 & $440(0.8)$ & $627(3)$ & $501(4.1)$ \\
\hline \multicolumn{19}{|c|}{ 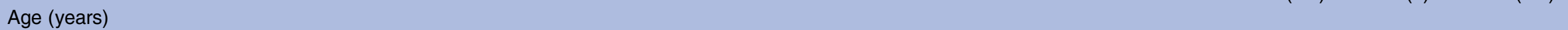 } \\
\hline$<20$ & 8933 & 788 & 44 & 3.2 & 5.2 & 2.6 & 3.4 & 6.2 & 3.3 & 5.7 & 15 & 146 & 731 & 60 & $1 \varepsilon$ & 64 & 22 & $2(4.6)$ \\
\hline 20-29 & 10527 & 2860 & 210 & 4.0 & 5.6 & 2.9 & 4.3 & 7.1 & 4.0 & 87928.4 & 181 & 85672.5 & 125091 & 33 & 587 & 72 & 3.7) & $2(1)$ \\
\hline $30-39$ & 14862 & 5266 & 586 & 5.0 & 6.3 & 4.3 & 5.3 & 7.9 & 9.1 & 96429.1 & 203134.2 & 171943.7 & 137494 & 283891 & 230779 & $111(0.7)$ & $245(4.7)$ & 25 (4.3) \\
\hline $40-49$ & 17465 & 7160 & 1708 & 6.0 & 7.0 & 5.2 & 6.4 & 8.7 & 7.0 & 117771.5 & 222320.8 & 223097.5 & 163727 & 303530 & 299184 & $148(0.8)$ & $314(4.4)$ & 79 (4.6) \\
\hline 50-59 & 19208 & 8619 & 4258 & 7.2 & 7.5 & 6.1 & 7.8 & 9.0 & 8.6 & 131882.9 & 216825.3 & 225620.7 & 183983 & 296830 & 304291 & 195 (1) & 320 (3.7) & $174(4.1)$ \\
\hline $60-69$ & 13396 & 6093 & 5727 & 9.5 & 8.2 & 7.9 & 10.7 & 10.9 & 13.8 & 157362.1 & 202838.8 & 291869.0 & 205801 & 273636 & 390158 & 135 (1) & $191(3.1)$ & 275 (4.8) \\
\hline$\geq 70$ & 12408 & 4867 & 6473 & 13.3 & 9.4 & 9.7 & 15.3 & 11.8 & 13.9 & 233606.0 & 248595.8 & 321709.3 & 284758 & 316882 & 413017 & $163(1.3)$ & $156(3.2)$ & $284(4.4)$ \\
\hline \multicolumn{19}{|c|}{ (1) } \\
\hline \multicolumn{19}{|l|}{ Gender } \\
\hline Male & 2535 & 3760 & 2383 & 12.2 & 12.1 & 12.7 & 13.5 & 16.5 & 18.8 & 261 & 77.8 & & & 258 & & & 8.5) & 5.5) \\
\hline Female & 4341 & 5786 & 4755 & 15.2 & 12.7 & 12.3 & 16.5 & 15.1 & 15.3 & 328645.7 & 451277.4 & 476146.9 & 435491 & 607549 & 631362 & 56 (1.3) & $344(6)$ & $255(5.4)$ \\
\hline \multicolumn{19}{|l|}{ Age (years) } \\
\hline$<20$ & 71 & 86 & 6 & 7.2 & 11.7 & 4.3 & 7.5 & 16.0 & 5.5 & 174687.2 & 444109.2 & 244083.3 & 242313 & 610245 & 329338 & $0(0)$ & $6(7)$ & $0(0)$ \\
\hline 20-29 & 341 & 473 & 28 & 7.3 & 10.3 & 4.0 & 8.3 & 13.6 & 5.0 & 191606.3 & 391898.4 & 183346.1 & 276101 & 555159 & 273754 & $0(0)$ & 34 (7.2) & $0(0)$ \\
\hline 30-39 & 672 & 1033 & 122 & 8.7 & 12.6 & 5.5 & 9.2 & 17.1 & 7.8 & 191615.9 & 506887.8 & 210689.7 & 276117 & 702295 & 290961 & $6(0.9)$ & $97(9.4)$ & $4(3.3)$ \\
\hline $40-49$ & 1018 & 1643 & 445 & 9.6 & 12.2 & 8.8 & 10.1 & 15.1 & 11.1 & 219955.0 & 464857.9 & 392506.9 & 310927 & 638448 & 534569 & $4(0.4)$ & $138(8.4)$ & 19 (4.3) \\
\hline $50-59$ & 1621 & 2507 & 1391 & 11.8 & 12.1 & 9.3 & 12.7 & 14.4 & 11.7 & 267612.6 & 421782.8 & 376752.8 & 372247 & 580843 & 525597 & $14(0.9)$ & $154(6.1)$ & $67(4.8)$ \\
\hline $60-69$ & 1691 & 2155 & 2356 & 15.4 & 12.2 & 12.1 & 17.1 & 15.8 & 16.5 & 317361.9 & 443174.7 & 489538.3 & 422422 & 599557 & 651039 & $12(0.7)$ & $158(7.3)$ & $137(5.8)$ \\
\hline$\geq 70$ & 1684 & 1877 & 2963 & 19.8 & 12.4 & 14.3 & 21.7 & 15.2 & 19.1 & 408677.5 & 424968.8 & 536943.4 & 515407 & 551966 & 702443 & $33(2)$ & 79 (4.2) & $182(6.1)$ \\
\hline
\end{tabular}

*Patients with overlapping records tallied as one patient (overlapping not allowed).

†The number of outpatient visits or hospitalised days of patient indicated in the submitted insurance claim statement.

$\ddagger$ The number of reimbursed days includes the number of outpatient visits or hospitalised days and in-care drug prescription days. Outpatient visits or hospitalisation coinciding with drug prescription on the same day was tallied as 1 day.

$\S$ The amount of benefit paid by the insurer (Korean National Health Insurance Service) to the medical care institution, excluding self-payment cost paid by the beneficiary (patient), out of total treatment amount (or medication cost) determined to be valid through HIRA review.

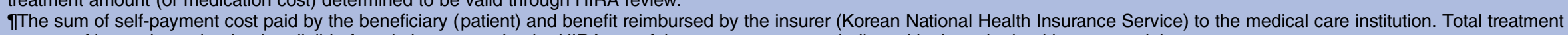
amount of items determined to be eligible for reimbursement by the HIRA out of the treatment amount indicated in the submitted insurance claim statement.

HIRA, Health Insurance Review and Assessment Service; IDD, intervertebral disc disorder; LBP, low back pain; nLBP, non-specific low back pain; SS, spinal stenosis. 
reported to increase with age in men and women. ${ }^{28}$ Our data suggest a greater frequency of all three most common lumbar disorders in women than in men, which is consistent with reports that women present with LBP more often than men. ${ }^{28}$ The reason may be partly attributed to gender role differences such as occupation, hours of work and occupational activities, including housework in addition to biological factors.

While clinics were the most frequently visited medical institution type in all three groups, the fact that Korean medicine clinics were next most frequently visited in the nLBP group is a point worthy of interest. Orthopaedics was the most frequently visited medical specialty in all three groups, followed by internal Korean medicine and acupuncture and moxibustion medicine specialties in the nLBP group. The Korean medical system is characterised by a dual, mutually exclusive medical system of conventional and Korean traditional medicine, and these circumstances are reflected in the high proportion of Korean medicine use for common lumbar disorders. These results are also concordant with survey results on the perception and usage of Korean medicine reporting LBP to be the most frequent reason for Korean medicine use $(12.9 \%){ }^{29}$

The average treatment amounts per patient in inpatient and outpatient care were highest in the SS group, and long-term care hospitals had highest treatment amounts in all three groups, followed by Korean medicine hospitals and upper level general hospitals in medical institutions. Long-term care hospitals are defined as medical institutions that provide medical services by conventional medicine or Korean medicine doctors for $\geq 30$ patients according to Korean medical law. However, long-term care hospitals are allowed more lenient standards in physician and nurse stationing than other hospitals through additional placement of social welfare workers or physiotherapists. As this study included billing data of patients with diagnoses for most common lumbar disorders in primary and four secondary diagnoses, billing data may have been inclusive of various diseases in elderly, end-term or palliative care patients, leading to higher costs in long-term care hospitals.

With regard to surgery rates, a proportion of $0.90 \%$ in the nLBP, $4.59 \%$ in the IDD and $4.85 \%$ in SS group received surgery, which, though slightly higher as data duplication may have occurred in the extraction process, is similar to Statistics Korea data. According to 2011 national statistics on major surgeries, of 1702638 patients who received medical care for M51 (other IDDs), 57931 $(3.40 \%)$ underwent surgery, which was the sixth most common reason for surgery, and of 1087162 M48 (other spondylopathies) patients, $31077 \quad(2.86 \%)$ received surgery, which was tallied as the 13th most common reason of all surgeries. ${ }^{30}$ In the USA, the prevalence of lumbar fusion surgery has shown a $220 \%$ increase from 1990 to $2001,{ }^{31}$ and it is estimated that 250000 laminectomies are conducted each year as of $2002 .{ }^{32}$
The most frequently used injection code in all three groups was epidural nerve block (lumbar and/or caudal), and the most frequently prescribed physiotherapy was deep heat therapy in all three groups. Non-opioid analgesic use was also similar in all three groups, with aceclofenac $100 \mathrm{mg}$ used most commonly, displaying high consistency in treatment procedures, especially considering that these lumbar disorders do not share a common aetiology, severity or prognosis. This high concordance may be due to personal preference or institutional policy, and though there is the added possibility of misclassification of codes or data, as patients pay a fee for service for all healthcare services, such errors should not have occurred.

A recent report on injection treatment in Korea states that $10.8-11.5 \%$ of all patients with LBP receive injection treatment, and that this number is steadily growing. Costs of injection treatment in patients with LBP were estimated to be 15.6 billion KRW in 2006, 17 billion in 2007 and 19.1 billion in 2008, which takes up 3\% of the total annual medical expenses for LBP. ${ }^{18}$

A 2007 US study using 5\% samples of Centers for Medicare and Medicaid Services outpatient claims data from 1994 to 2001 evaluated trends and medical expenses of lumbosacral injection treatment for patients with LBP. ${ }^{33}$ Participants were limited to patients aged 65 or older as the study population was from Medicare, and LBP-related lumbosacral diseases covered degenerative changes, SS, radiculopathy or sciatica, intervertebral disc displacement, osteoarthritis, spondylolisthesis and lumbosacral sprain. Considered injection treatments included epidural steroid injections, facet joint injections, sacral joint injections and current trends in fluoroscopy were also investigated. Results showed that use of epidural steroid injections increased $271 \%$ from 553 patients per 100000 in 1994 to 2055 in 2001, and facet joint injections increased during the same period from 80 to 264. Similar trends were observed in sacral joint injections, for which codes have been used since 2000, which rose steeply from 100 in 2000 to 212 in 2001. Total Medicare costs for lumbosacral injections have increased from US\$24 million in 1994 to US\$175 million in 2001. In terms of total inflation-adjusted reimbursed costs per injection, costs rose from US\$115 in 1994 to US\$227 in 2001.

In the comparison between injection treatment recipients and non-recipients, $6876(6.16 \%)$ of 111544 patients with nLBP, $9546(19.72 \%)$ of 48413 patients with IDD and 7138 (24.75\%) of 28842 patients with SS received injection treatment. A total $1.0 \%$ in the nLBP, $7 \%$ in the IDD and $5.7 \%$ in the SS injection subgroup received surgery, which is higher in all groups than for the non-injection subgroups. The average expenditure per patient was higher in the injection compared to the non-injection subgroup in all three groups (407083 KRW in nLBP, $615312 \mathrm{KRW}$ in IDD and $648545 \mathrm{KRW}$ in SS). This disparity in medical usage in the injection and non-injection subgroups is probably due to symptom 
severity, general health (including comorbidities), accessibility to healthcare and socioeconomic differences, but clinical factors could not be comprehensively analysed or adjusted for as with other studies retrospectively using claims databases.

This study used nationwide data records relating to common lumbar disorder diagnoses. However, the current disease classification system used at HIRA cannot identify pain specific to the lumbar area, and as most frequent lumbar disorders in up to four secondary diagnoses were selected in addition to the primary diagnosis in the current study, definitions of LBP and lumbar disorders relying solely on claims disease diagnosis have limited accuracy. We attempted to redeem this potential error by hypothesising that patients with LBP and lumbar disorder would require plain radiography for diagnosis and treatment, and included plain lumbar radiographs as a selection criterion, but the possibility of selection bias remains. Further consideration should be given to accurate selection in future studies using claims databases. Moreover, the accuracy of disease classification has been reported to be higher in inpatients than in outpatients, in severe disorders than in common mild disorders and in general hospital levels than in clinics. ${ }^{34}$

Though HIRA patient sample data are extracted from extensive raw data in a systematic manner, these secondary data are presented by estimate and therefore the sample size needs to be sufficiently large to establish representativeness and significance. The explanatory power of samples inevitably increases with higher frequency in inpatient populations and common disease classification, and decreases with lower frequency disease classifications. While the present study secures certain representativeness and generality as the subject matter was high prevalence lumbar disorders in Korea, weighted data of samples may still show a relatively high SD or SE.

An additional limitation of this study is that disease subcategories with distinct characteristics are presented together under single categories. For example, M511 (lumbar disorders and other IDDs with radiculopathy), which is diagnosed in cases with radiculopathy associated with lumbar IDD, takes up $\sim 49.11 \%$ of the IDD group. The IDD group additionally comprises such codes as M513 (other specified intervertebral disc degeneration, multiple sites in the spine; $6.02 \%$ of the IDD group) and M519 (IDD, unspecified; $10.72 \%$ of the IDD group), and considering that radiculopathy holds significant clinical relevance as a diagnosis point, lumping of different diagnosis codes into groups for analysis may be a matter of concern. Still, in the process of designing the study, physicians in current practice were in concurrence that these codes are not clearly differentiated for diagnosis in actual clinical practice settings in Korea, and analysis was performed in primary and secondary diagnoses in accordance with the opinion that various issues may be taken into account (eg, private insurance, medical care institution characteristics, individual differences in physicians) in category division and that primary and secondary diagnoses are generally used in conjunction.

Other limitations include that these results are crude presentations of current practice as socioeconomic and, as such, clinical factors influencing patterns of practice such as income, education level, residence, height, weight, mortality and health-related risk factors (eg, alcohol consumption, smoking, exercise) could not be analysed. Also, while fee-for-services for nationally covered healthcare services are comprehensively recorded in the claims database, non-reimbursable items and medicine such as over-the-counter drugs do not generate billing data. The short period additionally limited sample data analysis as determining incidence and disease duration (ie, acute, subacute, chronic stage) data by setting a washout period was not feasible. Future studies may compensate for these limitations through anonymous patient data sharing between medical institutions or governing bodies (eg, hospital medical records with personal information protected, National Health and Nutrition Examination Survey data and National Health Examination data).

\section{CONCLUSIONS}

In summary, the results of this study demonstrate distinct differences in patterns of medical care use and costs of most frequent lumbar disorders in national-level patient sample data, and should be considered in establishing guidelines for usual care in health policy and budget appropriation to provide a standard for the appropriate level of management and decision-making in common lumbar disorders in Korea.

\section{Author affiliations}

${ }^{1}$ Jaseng Spine and Joint Research Institute, Jaseng Medical Foundation, Seoul, Republic of Korea

${ }^{2}$ Clinical Research Division, Korea Institute of Oriental Medicine, Daejeon, Republic of Korea

${ }^{3}$ University of Science \& Technology (UST), Korean Medicine Life Science, Campus of Korea Institute of Oriental Medicine, Daejeon, Republic of Korea

Contributors Y-JA, J-SS, JL, YJL and I-HH drafted the study, and Y-JA, M-RK and I-HH wrote the final manuscript. Y-JA, J-SS, JL, YJL, M-RK, JHL, K-MS, KBP and I-HH contributed to acquisition of data and the study design and made critical revisions. Y-JA, KBP, JHL, K-MS and I-HH contributed to analysis and interpretation of data. All of the authors have read and approved the final manuscript.

Funding This study was supported by the Korea Institute of Oriental Medicine, K16123.

Competing interests None declared.

Ethics approval The study was approved by the Institutional Review Board (IRB) of Jaseng Hospital of Korean Medicine in Seoul, Korea (IRB approval number: KNJSIRB2015-55). Written informed consent was not obtained from participants for their clinical records to be used as this study used national billing data submitted to HIRA. Patient information was anonymised and de-identified by HIRA prior to analysis in this study.

Provenance and peer review Not commissioned; externally peer reviewed.

Data sharing statement HIRA data are third-party data not owned by the authors. HIRA data are available upon visit or by mail upon direct, email or fax submission of the data set request form and declaration of data use that is 
downloadable from the 'HIRA' website (http://www.hira.or.kr/dummy.do? pgmid=HIRAA070001000450) and upon payment of the transfer of data request fee (300 $000 \mathrm{KRW}$ per data set)

Open Access This is an Open Access article distributed in accordance with the Creative Commons Attribution Non Commercial (CC BY-NC 4.0) license, which permits others to distribute, remix, adapt, build upon this work noncommercially, and license their derivative works on different terms, provided the original work is properly cited and the use is non-commercial. See: http:// creativecommons.org/licenses/by-nc/4.0/

\section{REFERENCES}

1. Weksler N, Velan GJ, Semionov M, et al. The role of sacroiliac joint dysfunction in the genesis of low back pain: the obvious is not always right. Arch Orthop Trauma Surg 2007;127:885-8.

2. Weinstein JN. Anatomy and neurophysiologic mechanisms of spinal pain. In: Frymoyer JW, ed. The adult spine. Principles and practice. 1st edn. New York: Raven Press, 1991.

3. Harkness EF, Macfarlane GJ, Silman AJ, et al. Is musculoskeletal pain more common now than 40 years ago?: two population-based cross-sectional studies. Rheumatology (Oxford) 2005;44:890-5.

4. Freburger JK, Holmes GM, Agans RP, et al. The rising prevalence of chronic low back pain. Arch Intern Med 2009:169:251-8.

5. Krismer M, van Tulder M, Low Back Pain Group of the Bone and Joint Health Strategies for Europe Project. Strategies for prevention and management of musculoskeletal conditions. Low back pain (non-specific). Best Pract Res Clin Rheumatol 2007;21:77-91.

6. Komori $\mathrm{H}$, Shinomiya K, Nakai O, et al. The natural history of herniated nucleus pulposus with radiculopathy. Spine 1996;21:225-9.

7. Martin BI, Deyo RA, Mirza SK, et al. Expenditures and health status among adults with back and neck problems. JAMA 2008;299: 656-64.

8. Kelsey JL, Ostfeld AM. Demographic characteristics of persons with acute herniated lumbar intervertebral disc. J Chronic Dis 1975;28:37-50.

9. Miller JA, Schmatz C, Schultz AB. Lumbar disc degeneration: correlation with age, sex, and spine level in 600 autopsy specimens. Spine 1988;13:173-8.

10. de Schepper El, Overdevest GM, Suri P, et al. Diagnosis of lumbar spinal stenosis: an updated systematic review of the accuracy of diagnostic tests. Spine 2013;38:E469-81.

11. Katz JN. Lumbar spinal fusion. surgical rates, costs, and complications. Spine 1995;20(24 Suppl):78S-83S.

12. Porter RW. Spinal stenosis and neurogenic claudication. Spine 1996;21:2046-52.

13. Zeifang F, Schiltenwolf M, Abel R, et al. Gait analysis does not correlate with clinical and MR imaging parameters in patients with symptomatic lumbar spinal stenosis. BMC Musculoskelet Disord 2008;9:89.

14. Johnsson KE. Lumbar spinal stenosis. A retrospective study of 163 cases in southern Sweden. Acta Orthop Scand 1995;66:403-5.
15. Athiviraham A, Wali ZA, Yen D. Predictive factors influencing clinical outcome with operative management of lumbar spinal stenosis. Spine J 2011;11:613-17

16. Kim JD, Son MS. 2013 national health insurance statistical yearbook. Seoul: Health Insurance Review and Assessment Service and National Health Insurance Service, 2014.

17. Health Insurance Review and Assessment Service. http://www.hira. or.kr/. Updated 2015

18. Lee SM, Hahn S, Kim J, et al. [Pain relief effects of injection therapy for patients with chronic back pain]. Seoul: National Evidence-based Healthcare Collaborating Agency (NECA), 2010;NECA-NA09-006 (12):1-232.

19. Kim LY, Sakong J, Kim Y, et al. Developing the inpatient sample for the national health insurance claims. Health Pol Manag 2013;23:152-61.

20. Britnell M. In search of the perfect health system. London: Palgrave Macmillan, 2015.

21. Health Insurance Review and Assessment Service. Guidelines for review and assessment for healthcare services of 2011. Seoul: Health Insurance Review and Assessment Service, 2011.

22. van Tulder MW, Koes BW, Bouter LM, et al. Management of chronic nonspecific low back pain in primary care: a descriptive study. Spine 1997;22:76-82.

23. Cherkin DC, Deyo RA, Wheeler K, et al. Physician variation in diagnostic testing for low back pain. Who you see is what you get. Arthritis Rheum 1994;37:15-22.

24. Cherkin DC, Deyo RA, Loeser JD, et al. An international comparison of back surgery rates. Spine 1994;19:1201-6.

25. Cherkin DC, Deyo RA, Wheeler K, et al. Physician views about treating low back pain. The results of a national survey. Spine 1995;20:1-9; discussion 9-10.

26. van Tulder M, Koes B, Assendelft $\mathrm{W}$, et al. The effectiveness of conservative treatment of acute and chronic low back pain. Amsterdam: EMGO Institute, Vrije Universiteit, 1999.

27. Berwick DM. Eleven worthy aims for clinical leadership of health system reform. JAMA 1994;272:797-802.

28. de Schepper El, Damen J, van Meurs JB, et al. The association between lumbar disc degeneration and low back pain: the influence of age, gender, and individual radiographic features. Spine 2010;35:531-6.

29. Yoon KJ. Use and perception of Korean medicine in Koreans. Korea Institute for Health and Social Affairs (KIHASA), 2012;140 (2012-21):1-8.

30. Twenty most frequent surgery types of 2011. http://kosis.kr/statHtml/ statHtml.do?orgld=350\&tblld=DT 35004 A072015

31. Martin $\mathrm{BI}$, Mirza SK, Comstock BA, et al. Reoperation rates following lumbar spine surgery and the influence of spinal fusion procedures. Spine 2007;32:382-7.

32. Slipman $\mathrm{CW}$, Shin $\mathrm{CH}$, Patel RK, et al. Etiologies of failed back surgery syndrome. Pain Med 2002;3:200-14; discussion 214-7.

33. Friedly J, Chan L, Deyo R. Increases in lumbosacral injections in the Medicare population: 1994 to 2001. Spine 2007;32:1754-60.

34. Park BJ, Seong JH, Park GD, et al. Studying on improving diagnosis codes in national health insurance claims data. Seoul, Korea: Health Insurance Review and Assessment Service, 2003. 